\title{
Impact of Combination of Natural and Synthetic Fibers on the Mechanical Properties of Concrete
}

\author{
Aamir Yousuf, Manish Kaushal, Nahal Mattoo
}

\begin{abstract}
Concrete has found its widespread application as a construction material. The use of different kinds of concrete have revolutionized the construction industry. Concrete as we know is very good in compression, however due to the development of micro cracks under tensile loading in concrete, the tensile strength of concrete is only 1/10th of its compressive strength. This drawback of concrete has been taken care of by the use of reinforcement in concrete. Rebars or reinforcement bars along with the concrete have added much to the tensile strength of concrete. Over the years steel bars, steel fibers and other materials have been used as reinforcement in concrete. Use of reinforcing bars in concrete caters the need of resisting tensile loads and thereby making Reinforced Cement Concrete an excellent construction material. However, the use of heavy steel bars as reinforcement makes concrete structures heavy and difficult to handle. In order to take care of this a new concept of reinforcement has been introduced i.e. reinforcing concrete with fibers. Different types of fibers have been used over the years as reinforcement in concrete. In this experimental study, combinations of two fibers have been used as a reinforcement. One of the fibers is a natural fiber i.e. coconut fiber and other one is a synthetic fiber i.e. polypropylene fiber. Both these fibers are used in combination with a specific percentage. In the first sample $0.5 \%$ of recron fiber was used and $0.25 \%$ of coconut fiber. In second sample $0.5 \%$ recron fiber was used and $0.75 \%$ of coconut fiber. The fiber reinforced concrete was then tested for compressive as well as tensile strength. The test results showed $29.4 \%$ and $5.3 \%$ increase in compressive strength, $32.3 \%$ and 48.9\% increase in split tensile strength and $40 \%$ and $80 \%$ increase in the flexural strength of concrete for both combinations respectively. Thus, making the concrete light weight and more resistant to cracking. This could be very useful in case of concrete pavements and slabs.
\end{abstract}

Keywords: Polypropylene, Coconut Fiber, Compressive Strength, Tensile Strength, Split Tensile Strength, Flexural Strength.

\section{INTRODUCTION}

With the advancement in technology no doubt world has experienced a revolution in construction industry but a little concern is shown towards putting eco friendly materials into use. Also, the use of waste materials in construction practices is an appreciated approach. In this experimental study coconut fiber, which actually is a waste material has been put to use as a natural fiber for reinforcement in concrete [1].

Revised Manuscript Received on December 30, 2019.

* Correspondence Author

Aamir Yousuf*, Department of Civil Engineering, RIMT University, Punjab, India. E-mail: aamiryousuf10@gmail.com

Manish Kaushal*, Department of Civil Engineering, RIMT University, Punjab, India. E-mail: manish.kaushal1@gmail.com

Nahal Mattoo, Department of Civil Engineering, Maharishi Dayanand University, Haryana, India. E-mail: naehal.mattoo@gmail.com

(C) The Authors. Published by Blue Eyes Intelligence Engineering and Sciences Publication (BEIESP). This is an open access article under the CC BY-NC-ND license (http://creativecommons.org/licenses/by-nc-nd/4.0/)
Another material used as a synthetic fiber reinforcement is polypropylene which is available commercially as Recron fiber at very cheap rate,making the project quite economical. In addition to thisKashmir Valley is included in earthquake Zone IV[2], therefore making it necessary to use lightweight concrete for construction. Fiber reinforced concrete is lightweight concrete and therefore much suitable for earthquake prone areas [3]. In this experimental study tests were conducted in order to study the effects of combination of natural and synthetic fibers on mechanical properties of concrete. The tests were done after casting cubes beams and cylinders consisting of two different percentages of fibers. In first sample $0.5 \%$ of recron fiber was used and $0.25 \%$ of coconut fiber and the sample was named CMB1. In second sample $0.5 \%$ recron fiber was used and $0.75 \%$ of coconut fiber. The percentage of fibers used was calculated as per the combined weight of cement and sand.

\section{MATERIALS}

\section{A. Cement}

Cement used in the project was ordinary Portland cement having 43 Grade. The cement was Khyber brand cement conforming to IS8112-2013[4]. The specific gravity of cement was 2.7 and consistency was 35\%.

\section{B. Fine Aggregates}

Sand used in the project was bought from Ganderbal area of Kashmir dredged out from Jhelum River.

\section{Coarse Aggregates}

Coarse Aggregates used are crushed stone aggregates ofsize $13 \mathrm{~mm}-20 \mathrm{~mm}$. The aggregates were tested for water absorption, specific gravity and Aggregate Crushing Value as per IS 2386 [5]. Following results were obtained:

Table I - Properties of Coarse Aggregates

\begin{tabular}{|c|c|}
\hline Tests & Results \\
\hline Specific Gravity & 2.6 \\
\hline Water Absorption & $0.22 \%$ \\
\hline Aggregate Crushing Value & $17 \%$ \\
\hline
\end{tabular}

\section{Water}

The water used in the experimental study was tap water having a ph of 7.4. The water was clean and free from anyvisible impurities. 


\section{E. Natural Fibers}

The natural fiber used was the coconut fiber which was bought from a local coconut vendor and was available with him as a waste material. The fibers were cut of $5 \mathrm{~cm}$ length so as to obtain a particular $\mathrm{l} / \mathrm{d}$ ratio.

\section{F. Synthetic Fibers}

The synthetic fibers used was polypropylenefiber commercially available as recron fiber under brand name of reliance. The fibers were of 3 cmlength. The fibers were available in 100 gm packets costing Rs 40 each.

\section{PREPERATION OF SAMPLES}

\section{A. Compressive Strength Test Samples}

Nine cubical samples were prepared in 150x150mm moulds. Concrete used for sample preparation was M20 nominal mix concrete with Cement:Sand:Coarse Aggregate ratio as $1: 1.5: 3$. Firstly all the materials were mixed dry and then coconut fiber was added as $0.5 \%$ of combined weight of cement and sand and recron as $0.25 \%$ of combined weight of cement and sand for CMB1 and $0.25 \%$ of coconut fiber and $0.5 \%$ of recron fiber for CMB2. After thoroughly mixing for about two minutes water was added, little at a time till the mixing process is complete. The w/c ratio was kept 0.55 , the reason for a higher w/c ratio being the ability of fibers to absorb water. The moulds were then greased and concrete placed in them in layers, giving each layer a good amount of tamping. After placing into the moulds, the moulds were kept on vibrator for 30 seconds so as to liberate any extra air entrapped and make sample more compact. After keeping concrete in moulds for 24 hrs the moulds were emptied and samples taken out.Three samples each of PCC, CMB1 and CMB2 were prepared.
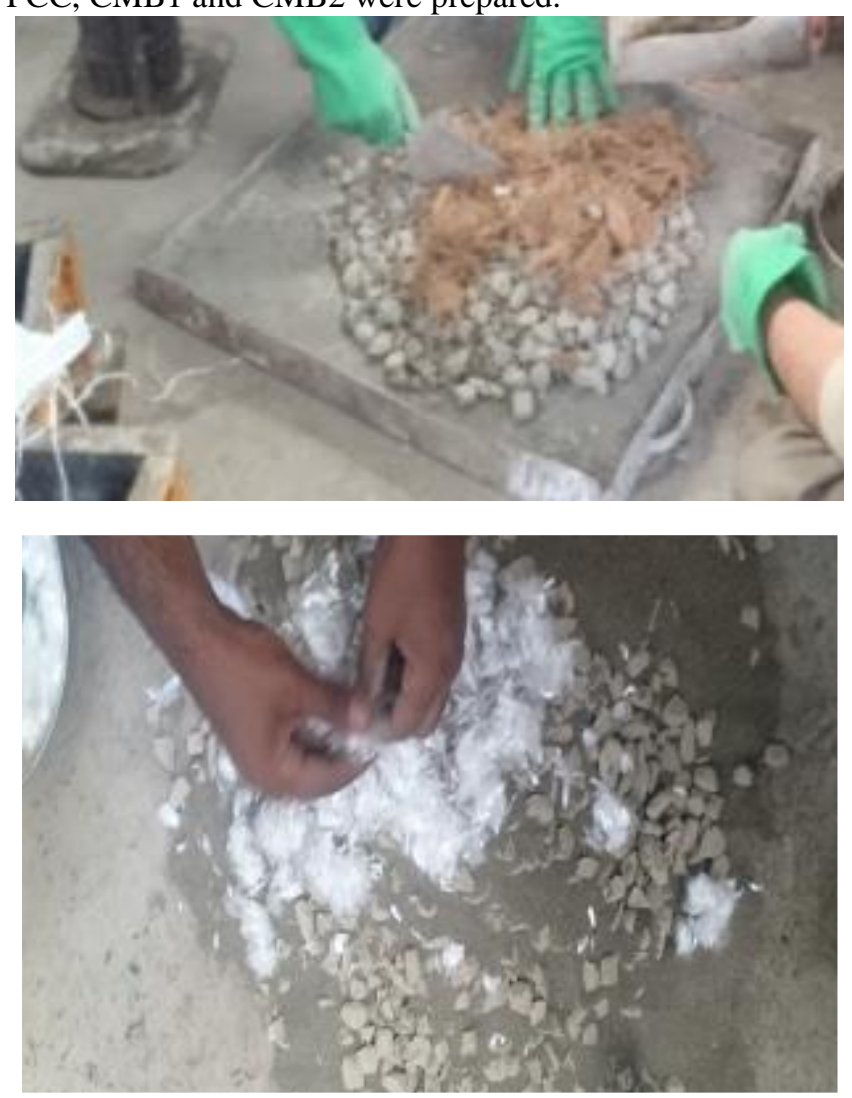

Figure 1 - Mixing of Coconut and Recron Fibers

\section{B. Split Cylinder Strength Test}

Six cylindrical samples were prepared in 300x150mm moulds. Concrete used for sample preparation was M20 nominal mix concrete with Cement:Sand:Coarse Aggregate ratio as $1: 1.5: 3$. Firstly all the materials were mixed dry and then coconut fiber was added as $0.5 \%$ of combined weight of cement and sand and recron as $0.25 \%$ of combined weight of cement and sand for CMB1 and $0.25 \%$ of coconut fiber and $0.5 \%$ of recron fiber for CMB2. After thoroughly mixing for about two minutes water is added, little a time till the mixing process is complete. The w/c ratio was kept 0.55 , the reason for a higher w/c ratio being the ability of fibers to absorb water. The moulds were then greased and concrete placed in them in layers, giving each layer a good amount of tamping. After placing into the moulds, the moulds were kept on vibrator for 30 seconds so as to liberate any extra air entrapped and make sample more compact. After keeping concrete in moulds for 24 hrs the moulds were emptied and samples taken out. Two samples each of PCC, CMB1 and CMB2 were prepared. After taking out the samples were kept in a curing tank.

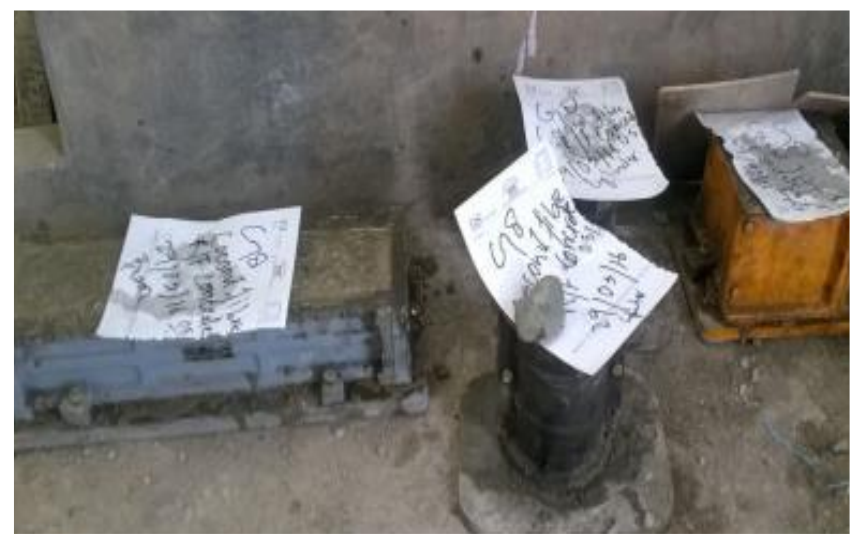

Figure 2 - Concrete Moulds

\section{C. $\quad$ Flexural Strength Test}

Sixsamples were prepared in 150x150x750mm moulds. Concrete used for sample preparation was M20 nominal mix concrete with Cement:Sand:Coarse Aggregate ratio as $1: 1.5: 3$. Firstly all the materials were mixed dry and then coconut fiber was added as $0.5 \%$ of combined weight of cement and sand and recron as $0.25 \%$ of combined weight of cement and sand for CMB1 and $0.25 \%$ of coconut fiber and $0.5 \%$ of recron fiber for CMB2. After thoroughly mixing for about two minutes water is added, little a time till the mixing process is complete. The w/c ratio was kept 0.55 , the reason for a higher w/c ratio being the ability of fibers to absorb water. The moulds were then greased and concrete placed in them in layers, giving each layer a good amount of tamping. After placing into the moulds, the moulds were kept on vibrator for 30 seconds so as to liberate any extra air entrapped and make sample more compact. After keeping concrete in moulds for 24 hrs the moulds were emptied and samples taken out. Two samples each of PCC, CMB1 and CMB2 were prepared. After taking out the samples were kept in a curing tank.

Published By:

Blue Eyes Intelligence Engineering \& Sciences Publication 


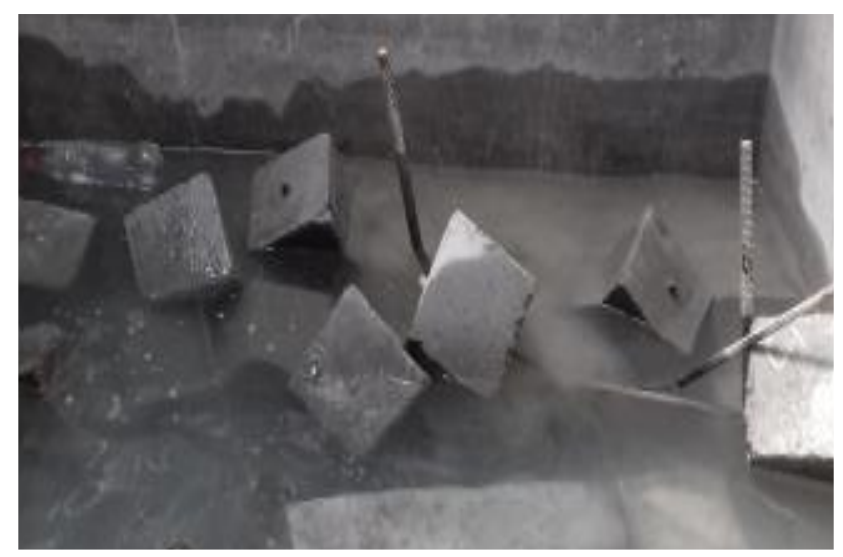

Figure 3 - Curing of Concrete Samples

\section{TESTS AND RESULTS}

In order to study the above experimental procedure, the following tests were performed:

\section{A. Slump Test}

The test is basically done to test workability of concrete. The test is done on wet concrete by placing it into a frustum cone like mould in three layers and then recording the displacement in the concrete. Following results were observed:

\section{Table II - Slump Test results of Concrete mixes}

\begin{tabular}{|c|c|c|}
\hline Sample & Slump (mm) & Change (\%) \\
\hline PCC & 50 & 0 \\
\hline CMB1 & 25 & $-50 \%$ \\
\hline CMB2 & 20 & $-60 \%$ \\
\hline
\end{tabular}

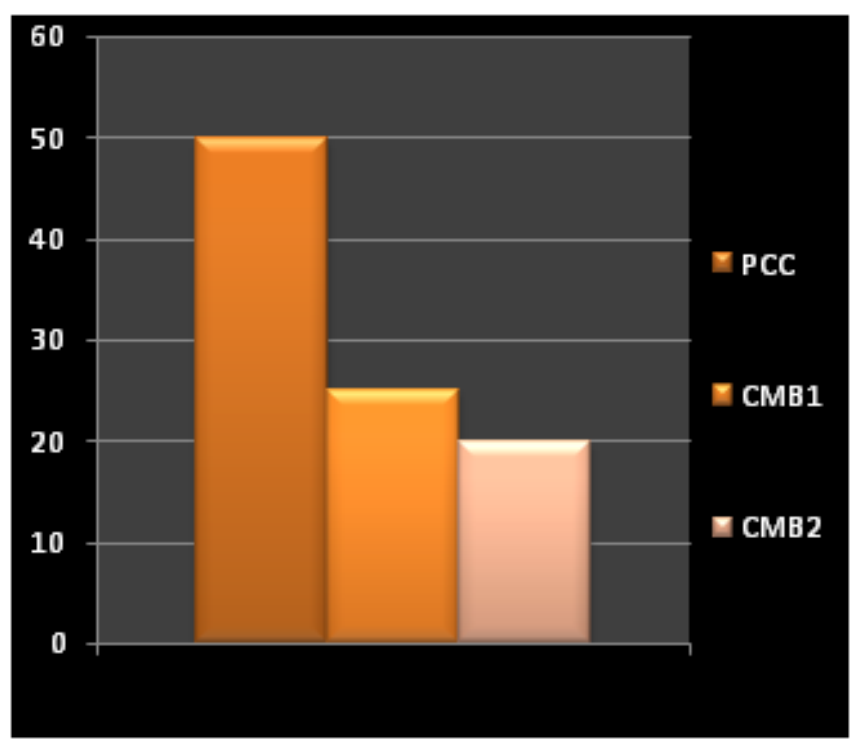

Figure 4 - Slump Test Graph

\section{B. Compressive Strength Test}

The test is performed on cubical samples of 150x150 mm in a machine called Compressive Testing Machine. The cubes are loaded and the load at which first crack appears is noted.That loads divided by the area of the loaded face gives the compressive strength of the sample.

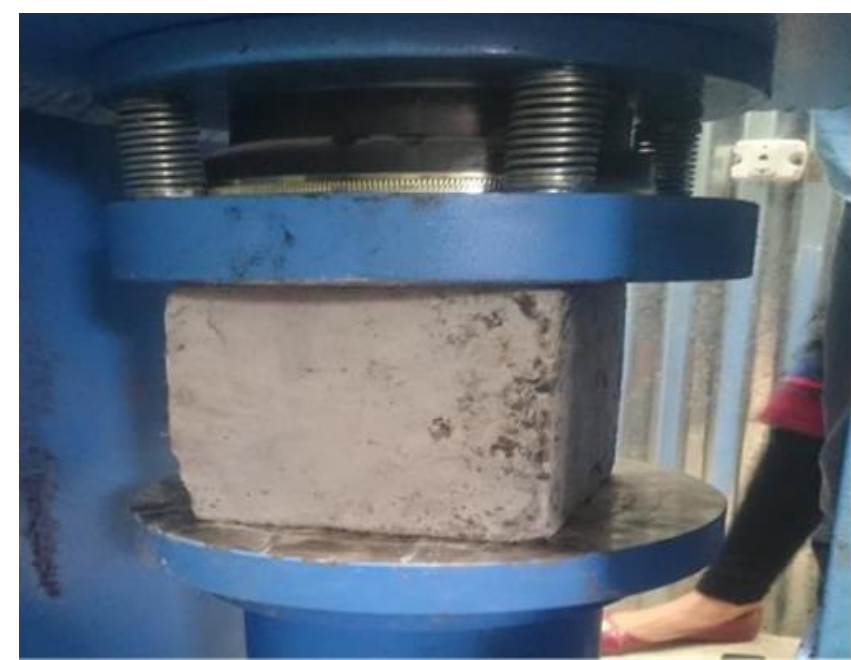

Figure 5 - Compressive Test of Cubes using CTM The following results were obtained:

Table III - Compressive Strength results of Samples

\begin{tabular}{|c|c|c|c|c|}
\hline \multirow{2}{*}{ Sample } & \multicolumn{3}{|c|}{ Compressive Strength(MPa) } & \multirow{2}{*}{ Increase(\%) } \\
\cline { 2 - 5 } & 7 Day & 14 Day & 28 Day & \\
\hline PCC & 15.33 & 19.6 & 22.22 & - \\
\hline CMB 1 & 19.68 & 25.65 & 28.76 & $29.4 \%$ \\
\hline CMB2 & 16.41 & 20.91 & 23.4 & $5.3 \%$ \\
\hline
\end{tabular}

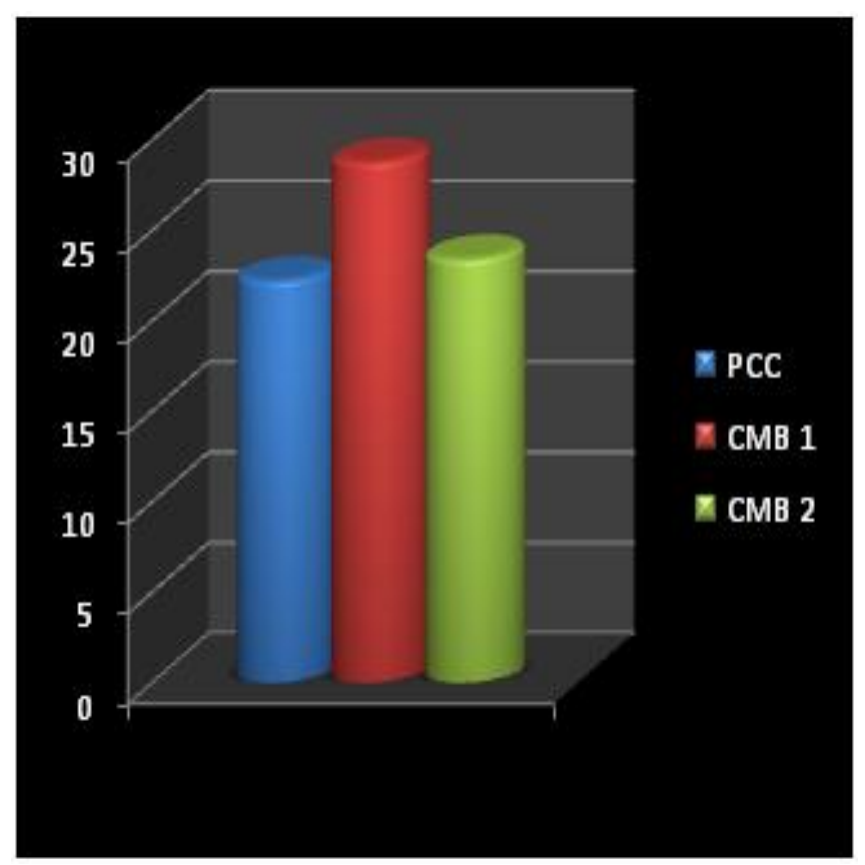

Figure 6 - Compressive Strength Graph

\section{Split Cylinder Strength Test}

The test is carried out on cylindrical specimens which are subjected to compressive loading arrangement. The cylinders are so placed that due to Poisson's effect the major portion experiences tensile loading. The following test results were obtained:

Published By:

Blue Eyes Intelligence Engineering \& Sciences Publication

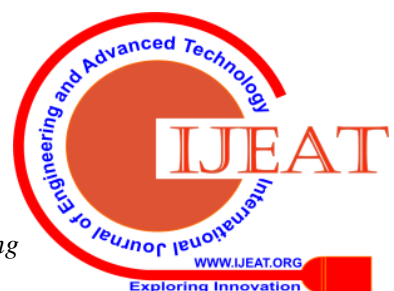


Table IV - Split Tensile Strength of Concrete Mixes

\begin{tabular}{|c|c|c|c|}
\hline \multirow{2}{*}{ Sample } & \multicolumn{2}{|c|}{ Split Tensile Strength (MPa) } & \multirow{2}{*}{ Increase \% } \\
\cline { 2 - 3 } & $\mathbf{1 4}$ Day & 28 Day & \\
\hline PCC & 2.46 & 2.82 & \\
\hline CMB 1 & 3.32 & 3.73 & $32.3 \%$ \\
\hline CMB 2 & 3.68 & 4.2 & $48.9 \%$ \\
\hline
\end{tabular}

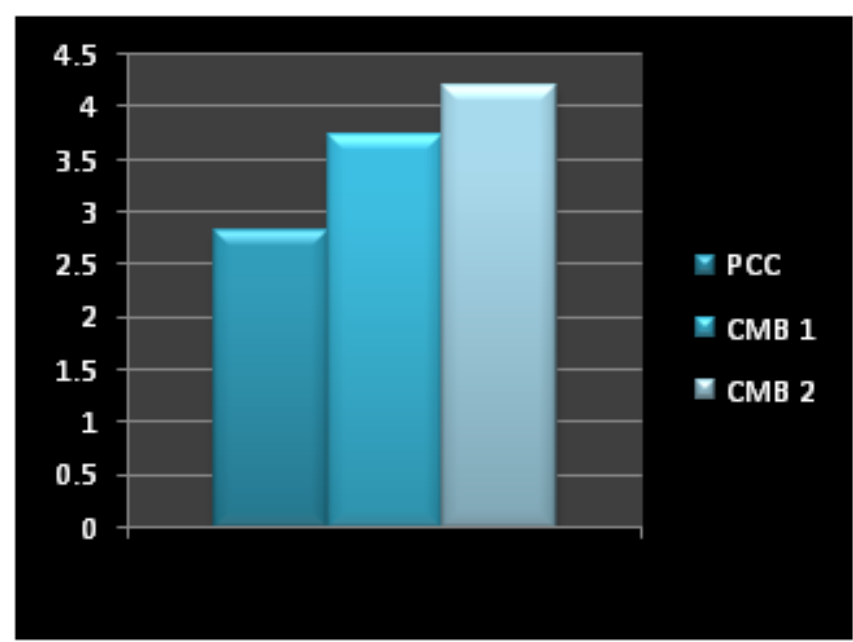

Figure 7 - Split Tensile Strength Graph

\section{Flexural Strength Test}

The test is done to check the tensile strength of a sample. The test is carried out on beams in a UTM machine. The specimen is subjected to two-point load arrangement. The following results were obtained:

Table V - Flexural Strength of Concrete Mixes

\begin{tabular}{|c|c|c|c|}
\hline \multirow{2}{*}{ Sample } & \multicolumn{2}{|c|}{ Flexural Strength (MPa) } & \multirow{2}{*}{ \% Increase } \\
\cline { 2 - 3 } & 14 Day & 28 Day & \\
\hline PCC & 2.96 & 3.5 & - \\
\hline CMB 1 & 4.25 & 4.9 & $40 \%$ \\
\hline CMB 2 & 5.58 & 6.3 & $80 \%$ \\
\hline
\end{tabular}

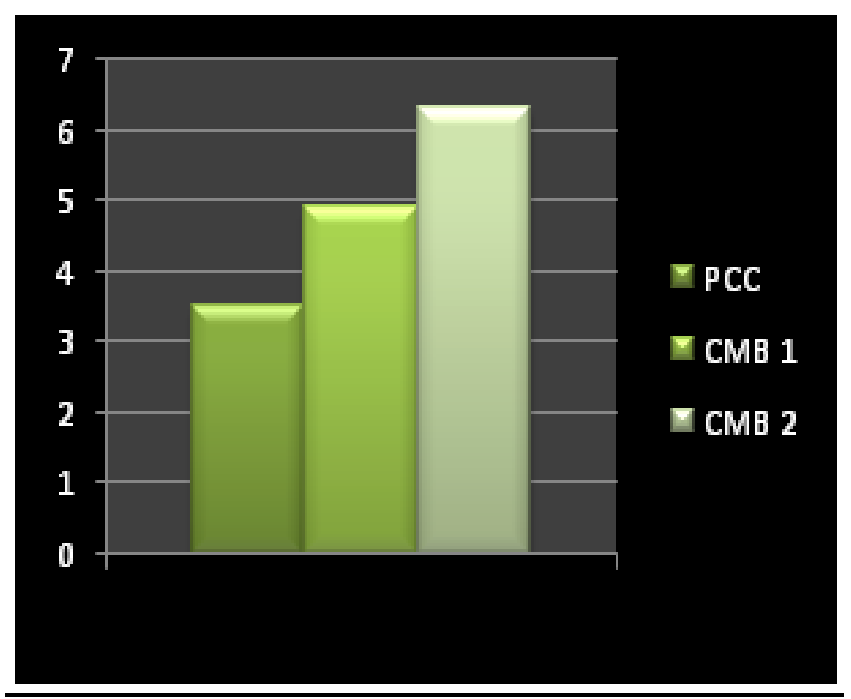

Figure 8 - Flexural Strength Graph

Retrieval Number: B3857129219/2019@BEIESP
Load Displacement Graphs: While testing the beams for flexural strength in UTM, the machine gives the value of displacement with the increasing load on the beam.

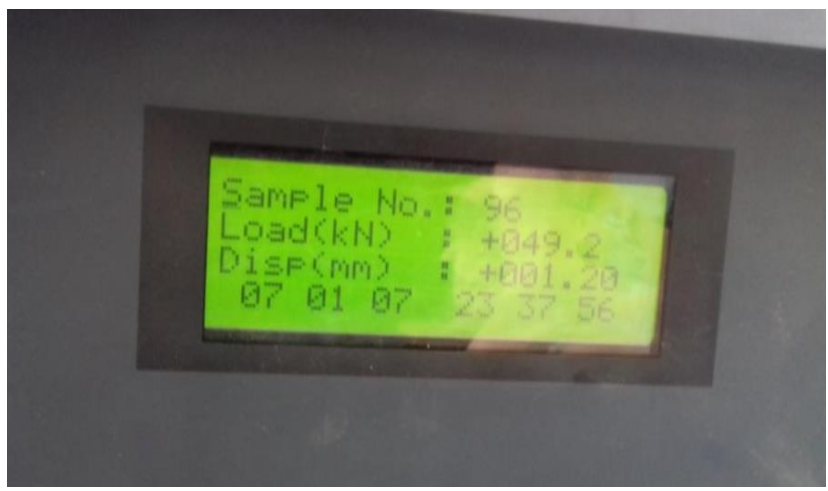

Figure 9 - Load Displacement Reading on UTM

\section{LOAD VS DISPLACEMENT FOR CMB 1}

- CMB 1 (0.5\% RECRON \& 0.25\% COCONUT FIBRE)

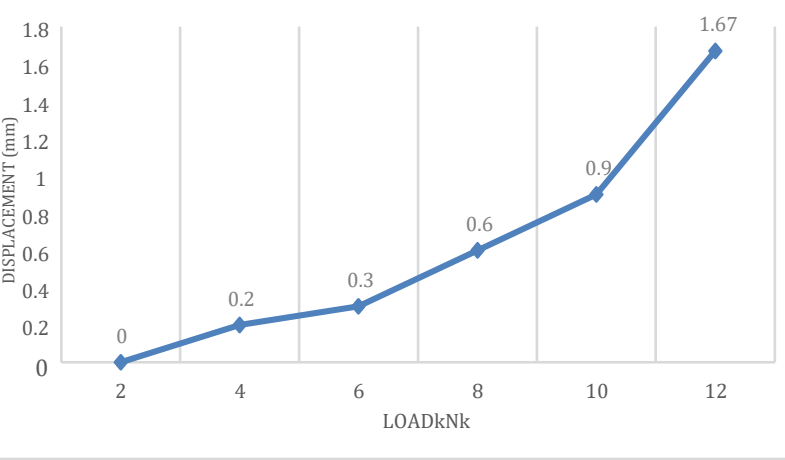

LOAD VS DISPLACEMENT FOR CMB 2

$\rightarrow$ CMB $2(0.5 \%$ RECRON \& $0.75 \%$ COCONUT FIBRE $)$

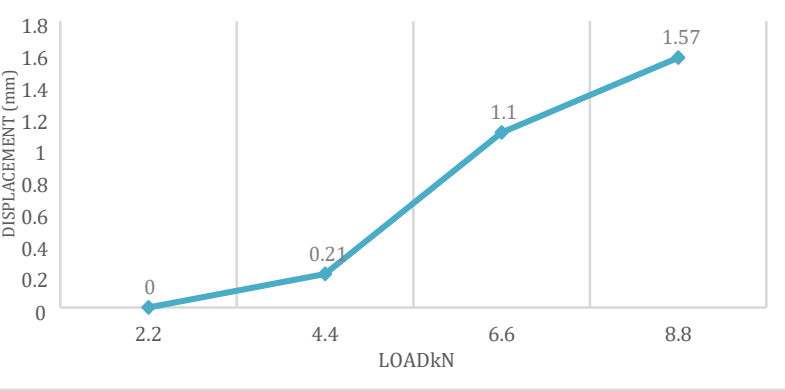

Figure 10 - Load Displacement Graphs

\section{CONCLUSIONS}

From the above tests the following conclusions can be drawn:

1. From the slump test, the slump of the sample CMB 2 was found out to be least. This indicates that polypropylene fiber absorbs more water than coconut. There was a decreased slump value in CMB 1 also but percentage change for $\mathrm{CMB} 1$ was only $50 \%$ while for CMB 2 it was $60 \%$ as compared to PCC.

2. The compressive strength of CMB1 was found out to be highest was $29 \%$ more than PCC,

Published By:

Blue Eyes Intelligence Engineering \& Sciences Publication

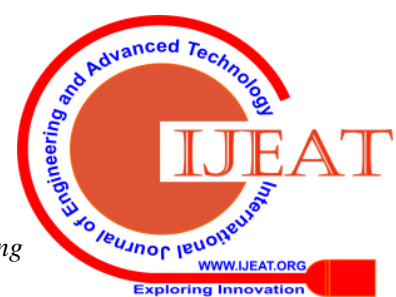


3. while for CMB 2 the percentage increase was only $5 \%$. This indicates that coconut fiber contributes more towards compressive strength as compared to recron.

4. The greater contribution of coconut fiber towards increase in compressive strength can be attributed to its higher $\mathrm{l} / \mathrm{d}$ ratio.

5. The split cylinder strength of CMB 2 was found to be highest and was 4.2 MPa. The split cylinder strength of sample CMB 1 was also greater than PCC. It indicates that both the fibers contribute to increase in split cylinder strength.

6. The flexural strength of $\mathrm{CMB} 2$ was found to be highest and was $80 \%$ more than PCC. For the sample CMB 1 flexural strength was 40\% more than PCC. However, the percentage increase for CMB 2 was double than CMB1 indicating that recron contributes more towards increase of flexural strength.

The results showed that the use of fibers in concrete enhances the tensile and flexural strength of the concrete considerably. Thus, making the concrete more durable and more resistant to cracks. This can be very useful in case of concrete pavements subject to wear \& tear and also for constructing slabs in light weight buildings.

\section{REFERENCES}

1. KshitijaNadgouda, Coconut fibre reinforced concrete. InternationalJournal of Mechanical and Production Engineering, ISSN: 2320-2092. Volume- 3, Issue-1, Jan.-2015.

2. Bureau of Indian Standards, IS 1893 (Part I)-2002. Earthquake zones in India.

3. Kotsovos, Gerasimos\&Zeris, Christos \&Kotsovos, Michael. (2007). The effect of steel fibres on the earthquake-resistant design of reinforced concrete structures. Materials and structures. 40. 175-188. 10.1617/s11527-006-9129-5.

4. Bureau of Indian Standards, IS 8112-2013. Ordinary Portland Cement, Grade 43.

5. Bureau of Indian Standards,IS 2386-1963. Methods of tests for aggregates for concrete.

\section{AUTHORS PROFILE}

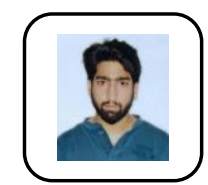

Aamir Yousuf, completed his B. Tech Civil from Islamic University of Science and Technology Awantipora Pulwama. Heis pursuing M. Tech in Structural Engineeringfrom RIMT University.

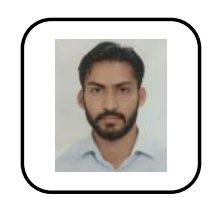

Manish Kaushal, received his B-Tech degree in civil engineering in 2011 from Punjab Technical University, Jalandhar, M-Tech from Punjab Technical University, Jalandhar in 2015.Presently, he is working as Assistant Professor in Department of Civil Engineering RIMT University, Punjab, India.

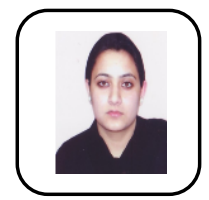

Nahal Mattoo, completed her B. Tech Civil from IUST Awantipora Pulwama. She completed her M. Tech in Structural Engineeringfrom Maharishi Dayanand University Rohtak. She is presently working as a Lecturer atDepartment of Civil Engineering, Kite Polytechnic College, Kashmir. 